\title{
Activity of eight antibacterial agents on Staphylococcus epidermidis attached to Teflon catheters
}

\author{
E. RAMIREZ DE ARELLANO, A. PASCUAL*, L. MARTINEZ-MARTINEZ and E. J. PEREA \\ Department of Microbiology, School of Medicine, University of Seville, Apdo 914, 41080 Seville, Spain
}

\begin{abstract}
Summary. The presence of a Teflon catheter had no effect on the in-vitro activity of a range of antibacterial agents against slime producing and non-producing Staphylococcus epidermidis strains as determined by a microdilution assay. The susceptibility of $S$. epidermidis attached to Teflon catheters for 6,24 and $48 \mathrm{~h}$ was also evaluated. MICs for planktonic and attached bacteria were similar. When bacteria attached to Teflon for $6 \mathrm{~h}$ were used as inocula, MBC values increased 32-8192-fold for the antibacterial agents tested. Similar results were observed when bacteria attached for 24 and $48 \mathrm{~h}$ were used as inocula. The activity of a high concentration $(16 \times \mathrm{MBC})$ of these antimicrobial agents against $S$. epidermidis biofilms in Teflon catheters was evaluated; for five slime non-producing strains, the highest reduction (around $99 \%$ ) in bacterial viability was produced by cloxacillin and teicoplanin; for the slime producers, the highest effect $(99.5 \%$ reduction) was shown by amikacin, clindamycin cloxacillin and ciprofloxacin but all cases still showed bacterial counts higher than $10^{3} \mathrm{cfu} / \mathrm{cath}$ ter segment. It is concluded that adherence of S. epidermidis to Teflon catheters decreases the bactericidal activity of the antibacterial agents tested in vitro.
\end{abstract}

\section{Introduction}

Staphylococcus epidermidis is an important cause of nosocomial infections, particularly in patients with indwelling catheters and other prosthetic devices. ${ }^{1,2}$ The increase in S. epidermidis infections is probably related to the increased use of prosthetic devices. ${ }^{2{ }^{23}}$

$S$. epidermidis grows on the surface of plastic catheters forming bacterial biofilms, ${ }^{4}$ and it is assumed that these biofilms contain large amounts of the same slime substance as that produced by the bacteria in vitro. Slime production has been considered as a mechanism related to increased resistance of $S$. epidermidis strains to antibacterial agents, but factors and mechanisms involved in the resistance of S. epidermidis biofilms have not been clearly defined. Several previous reports have documented increasing resistance of $S$. epidermidis to antibacterial agents when the bacteria are attached to plastic surfaces, ${ }^{5,6}$ although only a limited number of agents has been evaluated.

In this study, two aspects of the interactions among S. epidermidis, catheters and antibacterial agents are considered: firstly, the effect of a commonly used biomaterial, Tefion, on the activity of antibacterial agents against $S$. epidermidis; secondly, the susceptibility of S. epidermidis (slime producing and nonproducing strains) attached to Teflon, to the same antibacterial agents.

\section{Materials and methods}

\section{Bacterial strains}

Two clinical isolates of $S$. epidermidis were used: $\mathrm{C} 10$ (slime non-producer) and P15 (slime producer). Slime production in both strains was determined by a micromethod as described previously. ${ }^{7}$ Ten additional strains (five slime producers and five non-producers) from clinical sources were used for some experiments (see below).

\section{Biomaterial}

Catheters made from Teflon (Abbocath 16G, Abbott Laboratories) were used. For use in assays, catheters were cut into $0.5-\mathrm{cm}$ segments under sterile conditions.

\section{Antibacterial agents}

Amikacin (Bristol Myers), clindamycin (Upjohn), cloxacillin (Beecham), ciprofloxacin (Bayer), vancomycin (Lilly), teicoplanin (Merrell Dow), daptomycin (Lilly) and rifampin (Ciba-Geigy) were used as substances of stated potency.

\section{Susceptibility testing}

A microdilution assay was used according to the 
Table I. MIC and MBC of eight antimicrobial agents against two strains of $S$. epidermidis

\begin{tabular}{|c|c|c|c|c|}
\hline \multirow{2}{*}{$\begin{array}{c}\text { Antimicrobial } \\
\text { agent }\end{array}$} & \multicolumn{2}{|c|}{$\mathrm{C} 10$ (slime - ) } & \multicolumn{2}{|c|}{ P15 (slime +) } \\
\hline & $\mathrm{MIC}^{*}$ & MBC* & MIC* & $\mathrm{MBC}^{*}$ \\
\hline Amikacin & 1 & 1 & 0.5 & 1 \\
\hline Clindamycin & $0 \cdot 125$ & $0 \cdot 25$ & $0 \cdot 125$ & $0 \cdot 25$ \\
\hline Cloxacillin & 1 & 1 & 1 & 2 \\
\hline Ciprofloxacin & $0 \cdot 25$ & 0.5 & $0 \cdot 125$ & $0 \cdot 25$ \\
\hline Vancomycin & 2 & 2 & 0.5 & 1 \\
\hline Teicoplanin & 8 & 16 & 8 & 16 \\
\hline Daptomycin & 4 & 8 & 4 & 4 \\
\hline Rifampin & 0.003 & 0.007 & 0.007 & $0 \cdot 015$ \\
\hline
\end{tabular}

Slime - , non-producer; slime + , producer.

* $\mathrm{mg} / \mathrm{L}$

Table II. Effect of Teflon on the activity of antimicrobial agents against $S$. epidermidis strains $\mathrm{C} 10$ and P15. Data are expressed as ratio values between MIC or MBC with MIC $_{\text {cat }}$ or $\mathrm{MBC}_{\mathrm{cat}}$ ) and without (MIC or $\mathrm{MBC}$ ) catheter

\begin{tabular}{lccccc}
\hline \multirow{2}{*}{$\begin{array}{l}\text { Antimicrobial } \\
\text { agent }\end{array}$} & \multicolumn{2}{c}{$\mathrm{MIC}_{\text {eat }}^{*} / \mathrm{MIC}^{*}$} & & \multicolumn{2}{c}{$\mathrm{MBC}_{\text {cat }}^{*} / \mathrm{MBC}^{*}$} \\
\cline { 2 - 3 } \cline { 5 - 6 } & $\begin{array}{c}\mathrm{C} 10 \\
\text { (slime-) }\end{array}$ & $\begin{array}{c}\mathrm{P} 15 \\
\text { (slime }+)\end{array}$ & $\begin{array}{c}\mathrm{C} 10 \\
\text { (slime-) }\end{array}$ & $\begin{array}{c}\mathrm{P} 15 \\
\text { (slime+) }\end{array}$ \\
\hline Amikacin & 2 & 2 & & 2 & 1 \\
Clindamycin & 2 & 1 & & 1 & $0 \cdot 5$ \\
Cloxacillin & 1 & 1 & & 1 & $0 \cdot 5$ \\
Ciprofloxacin & 1 & 1 & & $0 \cdot 5$ & 1 \\
Vancomycin & 1 & 2 & & 1 & 2 \\
Teicoplanin & 1 & 1 & & $0 \cdot 5$ & $0 \cdot 5$ \\
Daptomycin & 1 & 1 & & 0.5 & 0.5 \\
Rifampin & 2 & 2 & & 1 & 1 \\
\hline * & & & & &
\end{tabular}

* mg/L.

NCCLS guidelines. ${ }^{8,9}$ To study the effect of the presence of Teflon, both MICs and MBCs were determined by the same methodology, except for the inclusion of a $0.5-\mathrm{cm}$ segment of catheter in each well of the microtitration plate.

Bacterial biofilms of $S$. epidermidis (both P15 and C10) were developed by static incubation of 50 segments of catheter in glass bottles containing $50 \mathrm{ml}$ of Mueller-Hinton broth inoculated with log-phase growth of the strain to be tested $\left(5 \times 10^{5} \mathrm{cfu} / \mathrm{ml}\right)$. Bottles were incubated for 6,24 or $48 \mathrm{~h}$ at $37^{\circ} \mathrm{C}$. To determine the number of attached bacteria, a segment of Teflon was washed three times in ice-cold phosphate-buffered saline (PBS, $\mathrm{pH} 7 \cdot 2-7 \cdot 4$ ) to remove loosely adherent inoculum, placed in $2 \mathrm{ml}$ of PBS, sonicated for $1 \mathrm{~min}$ in a sonicating bath at $45 \mathrm{kHz}$ (Ultrasons, Selecta, Spain) and vortex mixed at maximum speed for $15 \mathrm{~s}$. Under these conditions, bacterial biofilms were completely removed, as demonstrated by optical microscopy ${ }^{10}$. After dilution with ice-cold PBS, $10 \mu \mathrm{l}$ of the bacterial suspension were plated on Mueller Hinton agar (MHA) plates. After incubation $\left(37^{\circ} \mathrm{C}, 24 \mathrm{~h}\right)$ the number of cfu was counted.
Mean cfu values of bacteria in the biofilms were $1.0 \times 10^{4}(6 \mathrm{~h}), 2.5 \times 10^{5}(24 \mathrm{~h})$ and $3.0 \times 10^{5}(48 \mathrm{~h})$ for strain $\mathrm{C} 10$ and $1.0 \times 10^{5}(6 \mathrm{~h}), 1.0 \times 10^{6}(24 \mathrm{~h})$ and $1.0 \times 10^{6}(48 \mathrm{~h})$ for strain P15. MICs for the two strains were determined simultaneously by both the standard microdilution method and the modified method em. ploying bacterial biofilms on Teflon as inoculum. All the susceptibility assays were performed in parallel, with bacteria attached to catheter and the same number of planktonic bacteria as inocula. MICs were determined by the absence of turbidity in the broth (or surrounding each catheter piece when they were present) in each well. Standard MBCs were determined after subculturing $50 \mu \mathrm{l}$ of broth on to MHA. MBC was defined as a $99.9 \%$ reduction of the initial inoculum. When considering bacterial biofilms, $\mathrm{MBCs}$ were determined by washing twice with PBS, sonication and vortex mixing of Teflon segments, dilution and plating on MHA, as previously described. Variations in the replicate $\mathrm{MBC}$ determinations were \pm one dilution.

\section{Results}

$M I C$ and $M B C$ values of $S$. epidermidis in the absence of Teflon

The MIC and MBC values of a slime producing and a non-producing strain of $S$. epidermidis are shown in table I.

\section{Effect of Teflon on the activity of antimicrobial agents} against $S$. epidermidis

The effect of Teflon catheters on MIC and MBC values of the antimicrobial agents is presented in table II. The activity of none of the antimicrobial agents tested was significantly affected by the presence of the catheter.

\section{Susceptibility of S. epidermidis attached to Teflon catheters}

MIC values of the antimicrobial agents tested were similar when attached (for 6,24 or $48 \mathrm{~h}$ ) and planktonic bacteria were compared (table III). However, MBC values significantly increased when bacteria attached to Teflon were used as inocula. The results obtained with bacteria attached to Teflon for $6 \mathrm{~h}$ are shown in table IV. Under these conditions the MBC values of attached bacteria were $32->32768$ times higher than those obtained with planktonic bacteria. Among the antimicrobial agents tested, rifampin showed the greatest differences. This phenomenon did not depend on the capability of the strain to produce slime in vitro.

$\mathrm{MBC}$ values of all the antimicrobial agents increased when bacteria attached for 24 and $48 \mathrm{~h}$ (table IV) were 
Table III. Susceptibility to antimicrobial agents of two strains of S. epidermidis attached for 6, 24 and $48 \mathrm{~h}$ to Teflon

\begin{tabular}{|c|c|c|c|c|c|c|}
\hline \multirow{3}{*}{$\begin{array}{c}\text { Antimicrobial } \\
\text { agent }\end{array}$} & \multicolumn{6}{|c|}{$\mathrm{MIC}_{\mathrm{att}} / \mathrm{MIC}_{\mathrm{pl}}{ }^{*}$} \\
\hline & \multicolumn{3}{|c|}{$\mathrm{C} 10($ slime -$)$} & \multicolumn{3}{|c|}{ P15 (slime +) } \\
\hline & 6 & 24 & 48 & 6 & 24 & 48 \\
\hline Amikacin & 2 & 1 & 1 & 2 & 1 & 1 \\
\hline Clindamycin & 1 & 1 & 1 & 2 & 1 & 1 \\
\hline Cloxacillin & 1 & 2 & 2 & 2 & 1 & 1 \\
\hline Ciprofloxacin & 1 & 2 & 2 & 2 & 2 & 2 \\
\hline Vancomycin & 2 & 2 & 1 & 1 & 2 & 2 \\
\hline Teicoplanin & 1 & 1 & 1 & 1 & 2 & 2 \\
\hline Daptomycin & 2 & 1 & 1 & 2 & 2 & 1 \\
\hline Rifampin & 1 & 2 & 1 & 2 & 2 & 1 \\
\hline
\end{tabular}

* Data are expressed as ratio values between MIC with attached bacteria and MIC with planktonic bacteria. Inocula: strain C10: $1.5 \times 10^{4} \mathrm{cfu}(6 \mathrm{~h}), 2.5 \times 10^{5} \mathrm{cfu}(24 \mathrm{~h})$ and $3.0 \times 10^{5} \mathrm{cfu}(48 \mathrm{~h}) ;$ strain P15: $1.0 \times 10^{5} \mathrm{cfu}(6 \mathrm{~h})$ and $1.0 \times 10^{6} \mathrm{cfu}(24$ and $48 \mathrm{~h})$.

used as inocula. In these cases, the ratios were lower than those obtained at $6 \mathrm{~h}$, as the MBCs of planktonic bacteria were higher because of an inoculum size effect.

To establish whether or not this effect was strain dependent, a third series of experiments was performed with 10 additional $S$. epidermidis strains (five slime producers and five non-producers). Because of technical difficulties and the lengthy time required for the method described previously, in these experiments, catheter segments containing bacteria attached for $24 \mathrm{~h}$ were incubated in the presence of the different antimicrobial agents only at concentrations of $16 \times \mathrm{MBC}$ for $18 \mathrm{~h}$. After washing and sonication of catheter segments, the number of viable staphylococci/ segment was determined (table V). For the slime non-producing strains, the highest reduction (c. 99\%) in bacterial viability was produced by cloxacillin and teicoplanin but bacterial counts $>10^{3} \mathrm{cfu} /$ segment of catheter after incubation for $18 \mathrm{~h}$ were observed. For the slime-producing strains the highest reduction $(c$.
Table V. Effect of eight antimicrobial agents at concentrations corresponding to $16 \times \mathrm{MBC}$ on viability of $S$. epidermidis attached to Teflon catheters

\begin{tabular}{lcc}
\hline \multirow{2}{*}{$\begin{array}{c}\text { Antimicrobial } \\
\text { agent }\end{array}$} & \multicolumn{2}{c}{$\begin{array}{c}\text { Viable count }\left(\mathrm{cfu} \times 10^{3}\right) / \text { catheter } \\
\text { segment* }\end{array}$} \\
\cline { 2 - 3 } & slime - & slime + \\
\hline Control & $100(95)$ & $2000(185)$ \\
Amikacin & $8(11)$ & $11(19)$ \\
Clindamycin & $20(25)$ & $6(26)$ \\
Cloxacillin & $1(0 \cdot 8)$ & $10(17)$ \\
Ciprofloxacin & $13(23)$ & $14(14)$ \\
Vancomycin & $5(4)$ & $127(120)$ \\
Teicoplanin & $1(2)$ & $30(38)$ \\
Daptomycin & $18(26)$ & $126(160)$ \\
Rifampin & $3(4)$ & $212(205)$
\end{tabular}

* Results represent the mean (SEM) of three experiments with five strains each of slime producing and non-producing $S$. epidermidis.

$99.5 \%$ ) of bacterial viability in the biofilms was shown by clindamycin, amikacin, cloxacillin and ciprofloxacin, but bacterial counts $(>6-14) \times 10^{3} \mathrm{cfu} /$ segment of catheter were observed.

\section{Discussion}

In this study the effect of a plastic biomaterial commonly used to make intravascular catheters on the in-vitro activity of several antimicrobial agents against $S$. epidermidis and the activity of these antimicrobial agents against $S$. epidermidis attached to Teflon was evaluated.

There is not much information available on the interaction between plastic biomaterials and antimicrobial agents. In a previous report we described how other plastic biomaterials, such as siliconised latex could affect the activity of antimicrobial agents in vitro. The MIC values of meropenem against Pseudomonas aeruginosa were 32-64 times higher in the

Table IV. Susceptibility to antimicrobial agents of two strains of $S$. epidermidis attached for 6,24 and $48 \mathrm{~h}$ to Teflon

\begin{tabular}{|c|c|c|c|c|c|c|}
\hline \multirow{3}{*}{$\begin{array}{l}\text { Antimicrobial } \\
\text { agent }\end{array}$} & \multicolumn{6}{|c|}{$\mathrm{MBC}_{\mathrm{att}} / \mathrm{MBC}_{\mathrm{pl}} *$} \\
\hline & \multicolumn{3}{|c|}{$\mathrm{C} 10$ (slime - ) } & \multicolumn{3}{|c|}{ P15 (slime +) } \\
\hline & 6 & 24 & 48 & 6 & 24 & 48 \\
\hline Amikacin & $>512$ & $>256$ & $>128$ & $>256$ & $>128$ & $>128$ \\
\hline Clindamycin & $>1024$ & $>1024$ & $>512$ & $>512$ & $>128$ & $>128$ \\
\hline Cloxacillin & $>512$ & $>512$ & $>512$ & $>256$ & $>256$ & $>128$ \\
\hline Ciprofloxacin & $>4096$ & $>1024$ & $>1024$ & $>512$ & $>256$ & $>256$ \\
\hline Vancomycin & $>256$ & $>256$ & $>128$ & 128 & 32 & 32 \\
\hline Teicoplanin & $>64$ & $>64$ & $>64$ & $>32$ & $>16$ & $>16$ \\
\hline Daptomycin & $>512$ & $>64$ & $>64$ & 128 & $>32$ & $>32$ \\
\hline Rifampin & $>32768$ & $>32768$ & $>32768$ & $>8192$ & $>8192$ & $>8192$ \\
\hline
\end{tabular}

* Data are expressed as ratio values between $\mathrm{MBC}$ with attached bacteria and $\mathrm{MBC}$ with planktonic bacteria. Inocula: strain C10: $1.5 \times 10^{4} \mathrm{cfu}(6 \mathrm{~h}), 2.5 \times 10^{5} \mathrm{cfu}(24 \mathrm{~h})$ and $3.0 \times 10^{5} \mathrm{cfu}(48 \mathrm{~h})$; strain P15: $1.0 \times 10^{5} \mathrm{cfu}(6 \mathrm{~h})$ and $1.0 \times 10^{6} \mathrm{cfu}(24$ and $48 \mathrm{~h})$. 
presence of this biomaterial (A. Pascual, L. Martínez, E. Ramirez, E. J. Perea. Program of the 31st ICAAC, Chicago, USA. 1991 Abstract no. 1306). Moreover, siliconised latex elutes substances into the medium that could be metabolised by certain micro-organisms and impair the respiratory burst of human polymorphonuclear leukocytes. ${ }^{11,12}$ These data could indicate the importance of evaluating the interaction of new biomaterials with antimicrobial agents. None of the antimicrobial agents evaluated in this study was affected by the presence of Teflon catheters.

Previous reports have shown a poor activity of antimicrobial agents against bacterial biofilms. ${ }^{13} \mathrm{Un}$ fortunately, many of these reports examined only a limited number of antimicrobial agents. When considering the interaction between antimicrobial agents and bacterial biofilms, this study attempted to enlarge previous observations, with the evaluation of a higher number of both antimicrobial agents and strains. Moreover, the activity of antimicrobial agents against bacterial biofilms allowed to develop for different periods of time was also examined.

The data obtained demonstrate that the bacteristatic activity of the eight agents tested was similar for both planktonic and sessile bacteria, but the bactericidal activity was much lower for $S$. epidermidis attached to Teflon than for bacteria growing in broth. This is in agreement with the reports from Sheth et al. ${ }^{5}$ who described a similar phenomenon with $S$. epidermidis attached to polyvinylchloride, and from Evans and Holmes $^{6}$ who observed an increase in MBC values of $S$. epidermidis biofilms developed on an indwelling peritoneal catheter. Probably the most important limitation of this method is the use of catheters in a static state. Under these experimental conditions important factors such as a boundary layer with laminar flow (which is the usual situation in vivo) and turbulence are not evaluated. Nevertheless we consider that our data are probably closer to the situation in biomaterial-associated infections in vivo than those obtained from standard antibiograms.

The role of extracellular slime material in the decrease of antimicrobial activity against bacterial biofilms has been considered previously. In an effort to evaluate further the importance of slime production, five strains each of slime producing and non-producing $S$. epidermidis were exposed to concentrations of $16 \times$ MCB. For several antimicrobial agents (amikacin, clindamycin, cloxacillin and ciprofloxacin) similar numbers $\left(10^{3}-10^{5} \mathrm{cfu}\right)$ of organisms survived on the surface of the catheter, independently of the production of slime. Similar data have been reported by Gristina et al. ${ }^{14}$ who described an increase in the resistance of biofilms independently of the production of slime by the strains tested. The nature of slime is not well defined; it is assumed, but not proven, that the material surrounding $S$. epidermidis on the surface of the biomaterials is the same as the substance commonly detected in vitro and referred to as slime. Our data do not support a critical role for slime as the only mechanism of resistance to antimicrobial agents of bacterial biofilms. Other mechanisms could explain this phenomenon. A quiescent metabolic state or a low growth rate within the bacterial biofilm could be related to the tolerance observed for such a broad group of antimicrobial agents. ${ }^{15,16}$ The exact composition and biological nature of biofilms should be clarified before a more precise conclusion on the interaction with antimicrobial agents can be established.

The results from this and previous studies indicate the limited value of the current methodologies for defining the $\mathrm{MBC}$ of antimicrobial agents when considering biomaterial-associated infections. A consensus should be defined to standardise the evaluation of antimicrobial activity against bacterial biofilms.

We thank Mrs P. Hidalgo for typing the manuscript.

\section{References}

1. Morrison AJ, Freer CV, Searcy MA, Landry SM, Wenzel RP Nosocomial blood stream infections: secular trends in a statewide surveillance program in Virginia. Infect Control 1986; 7: 550-553.

2. Ponce de León S, Guenther SH, Wenzel RP. Microbiologic studies of coagulase-negative staphylococci isolated from patients with nosocomial bacteremias. J Hosp Infect 1986; 7: 121-129.

3. Martin MA, Pfaller MA, Wenzel RP. Coagulase-negative staphylococcal bacteremia. Mortality and hospital stay. Ann Intern Med 1989; 110: 9-16.

4. Peters G, Locci R, Pulverer G. Adherence and growth of coagulase-negative staphylococci on the surface of intravenous catheters. $J$ Infect Dis 1982; 146: 479-482.

5. Sheth NK, Franson T, Sohnle PG. Influence of bacterial adherence to intravascular catheters on in vitro antibiotic susceptibility. Lancet $1985 ; 2$ : 1266-1268.

6. Evans RC, Holmes CJ. Effect of vancomycin hydrochloride on Staphylococcus epidermidis biofilm associated with silicone elastomer. Antimicrob Agents Chemother 1987; 31 : 889-894.

7. Christensen GD, Simpson WA, Younger JJ et al. Adherence of

coagulase-negative staphylococci to plastic tissue culture plates: a quantitative model for the adherence of staphylococci to medical devices. J Clin Microbiol 1985; 22: 996-1006.

8. National Committee for Clinical Laboratory Standards. Methods for dilution antimicrobial susceptibility tests for bacteria that grow aerobically. Second edition; approved standard. NCCLS Document M7-A2. Villanova, PA, NCCLS. 1990

9. National Committee for Clinical Laboratory Standards Methods for determining bactericidal activity of antimicrobial agents; proposal guidelines. NCCLS Document M26-P. Villanova PA. NCCLS. 1987.

10. Sheth NK, Rose HD, Franson TR, Buckmire FLA, Sohnle PG In vitro quantitative adherence of bacteria to intravascular catheters. J Surg Res 1983; 34: 213-218.

11. Lopez-Lopez G, Pascual A, Martínez Martínez L, Perea EJ. Effect of a siliconized latex urinary catheter on bacterial adherence and human neutrophil activity. Diagn Microbiol Infect Dis 1991; 14: 1.6 .

12. Martínez-Martinez L, Pascual A, Perea EJ. Effect of three plastic catheters on survival and growth of $P$. aeruginosa. J Hosp Infect 1990; 16: 311-318.

13. Farber BF, Kaplan MH, Clogston AG. Staphylococcus epi- 
dermidis extracted slime inhibits the antimicrobial action of glycopeptide antibiotics. J Infect Dis $1990 ; 161$ : 37-40.

14. Gristina AG, Jennings RA, Naylor PT, Myrvik QN, Webb LX. Comparative in vitro antibiotic resistance of surfacecolonizing coagulase-negative staphylococci. Antimicrob Agents Chemother 1989; 33: 813-816.
15. Brown MRW, Williams $P$. Influence of substrate limitation and growth phase on sensitivity to antimicrobial agents. $J$ Antimicrob Chemother 1985; 15 (Suppl A): 7-14.

16. Dalhoff A. Differences between bacteria grown in vitro and in vivo. J Antimicrob Chemother 1985; 15 (Suppl A): 175-195. 